\title{
Improving the Information System of University Management
}

\author{
Elena Y. Levina ${ }^{1}$, Gulshat M. Mustafina ${ }^{2}$, Venera M. Nigmetzyanova ${ }^{3}$, Radik M. Galiyev ${ }^{3}$, Natalya A. Chalkina ${ }^{4}$, \\ Svetlana I. Ashmarina ${ }^{5} \&$ Tatyana S. Yeremeyeva ${ }^{4}$ \\ ${ }^{1}$ The Institute of Pedagogic and Psychology of Professional Education of Russian Academy of Education, \\ Kazan, Russia \\ ${ }^{2}$ Kazan (Volga region) Federal University, Kazan, Russia \\ ${ }^{3}$ Naberezhnye Chelny Institute of Kazan Federal University, Naberezhnye Chelny, Russia \\ ${ }^{4}$ Amur State University, Blagoveschensk, Russia \\ ${ }^{5}$ Samara State University of Economics, Samara, Russia \\ Correspondence: Elena Y. Levina, The Institute of Pedagogic and Psychology of Professional Education of \\ Russian Academy of Education, Isaeva Street 12, Kazan, 420039, Russia. E-mail: \\ frau.levina2010@yandex.ru
}

Received: October 24, 2014 Accepted: December 3, 2014 Online Published: December 18, 2014

doi:10.5539/res.v7n1p109 URL: http://dx.doi.org/10.5539/res.v7n1p109

\begin{abstract}
University management is currently supported by information system providing storage and data structuring of information required. Managing the development and improvement of the educational process quality requires creation of a monitoring system covering all of its objects and various measurement tools, which monitors the set of all features. The paper presents the components of pedagogical management, considers indicators of pedagogical processes and methods of evaluation, which define the basis for monitoring the educational processes at the University. Also the structure of a software module is shown, that works on the principle of the expert system and identifies problem characteristics of the educational activity. The results of the experimental work show the effectiveness of the presented software, that supports management decision-making of university departments' leadership and faculty.
\end{abstract}

Keywords: university management, information system, management decision-making support, monitoring, diagnostics, indicators of educational activities

\section{Introduction}

\subsection{Background}

The present stage of the society development is characterized by the global informatization of all management areas, in particular the management of educational activities. It is now recognized that relevant, reliable and accurate information is one of the most important components of any organization management on equal terms with financial and human resources (Drucker et al., 2008; Meskon et al., 2009), and the introduction of new knowledge derived from the information processing into practice provides clear competitive advantages in the operation of the institution in the educational market.

The modern development of computer technology, the possibilities of mathematical modeling, the expansion of new domain areas, development of pedagogical measurement is inevitably linked to automated systems designing, processing techniques and mathematical models of pedagogical phenomena for solving the problems of management and organization of information services (Tarsky, 2004).

\subsection{Status of a Problem}

Such well-known software packages as "Dean", "Electronic dean's office", "Student", etc., have been used by universities for a long time and have given a good account of themselves. In Russia, at present, there is a practice of implementation of corporate information systems of the University providing information support to the adoption of administerial and financial decision-making, learning activities, the implementation of innovative projects in education and research activities, that as a whole would increase the efficiency of university management at all levels (Ivanchenko, 2011; Granichin \& Komarov, 2005; Kadakin et al., 2000; Molchanov, 
2002). Currently proposed (Miklushevsky et al., 2006) automated information systems, including a database unit, which maintain a single filing of student database, multicriteria data samples, performance account, work with curricula and programs, schedules planning, payment of scholarships, educational process, conducting all kinds of records and providing a single document. Each institution, as a rule, either develops its own information system of university management, including parametric blocks (Finances, Human Resources, Library, Students, etc.), or use ready-software for scientific, educational and administrative purposes (Naser, 2011). These information tools make it much easier to work with higher school records in administrative structures, provide information support of the university, but do not help to solve the problems of continuous monitoring to support management decision-making at all levels of the educational process management (students, teachers, and administrators).

It should be noted that the general description of pedagogical phenomena and laws at the level of purely qualitative assessments is clearly insufficient for evaluation of these processes and the establishment of their properties. Especially important is becoming a problem of creating software applications that provide support for surveillance studies of learning outcomes (Tomilin, 2012; Grinkrug et al., 2007.). Unfortunately, specialized software products that satisfy all aspects of educational monitoring are not available in the Russian market, and the complexity of pedagogical outcomes formalization due to the high variability (Levina, 2012) significantly complicates the process of taking the necessary immediate decisions.

The analysis of the works of the above authors and of the existing information systems of university management has shown the need to improve the system of monitoring the quality of education in the information system of university management.

\subsection{The Research Hypothesis}

The analysis of existing information systems of university management in terms of control showed that the potential of information systems and data processing methods are not fully utilized to achieve the strategic goal of the university - to improve the quality of education. This conclusion allows us to formulate a hypothesis of the study: to improve the performance of higher school it is required to develop and implement a monitoring system, including not only the collection and storage of information about the effectiveness of educational activities, but also the diagnosis and analysis of educational activity.

\section{Experimental}

\subsection{The Objectives of the Research}

We have identified the following research objectives: 1) To identify the parameters of the educational activities monitoring at the university and the determination of assessment methods; 2) Development of the software module for monitoring concept enhancing the university management efficiency; 3) implementation of the software and the assessment of its effectiveness to manage the educational activities at the University.

\subsection{Theoretical and Empirical Methods}

To test the hypotheses of the research theoretical methods were used (analysis, synthesis of domain area information) and empirical methods (methods of mathematical statistics, expertise).

\subsection{The Basis of the Research}

The research was conducted on the basis of the institutions that form part of the Kazan National Research Technical University named after A. N. Tupolev and Kazan State Power Engineering University.

\subsection{The Stages of the Research}

The research was conducted in three stages:

In the first stage indicators of educational activities were analyzed, monitoring parameters were selected and methods for their evaluation were defined. The concept of monitoring information system to solve the problems for improving the effectiveness of university management has been developed.

In the second stage a standalone software module was developed and implemented, comprising: data structures, data connections, methods of processing, storage, visualization of the results of educational activities. The research and diagnostics of higher school educational activities during the school year have been carried out. Monitoring parameters corridors have been defined. The results of the diagnostics have been received and the causes of monitoring parameters deviations have been found.

In the third stage the generalization of the results of the study was carried out, testing and examination of the software module in the Universities' units were conducted. 


\subsection{Evaluation Criteria}

Monitoring of educational activities at the University is based on the efficiency of the educational process (the test results of students' knowledge) represented in the structural and procedural plans. Evaluating the effectiveness of a software module was conducted on the basis of leadership expert opinion of departments and faculties of universities.

\subsection{Proceedings and Description of the Experiment}

At the initial stage of the research the object to evaluation was defined from the standpoint of the quality of the educational process. It was found out that this object may take different levels of education systems, different system components or factors affecting the result (Subetto, 2000; Selezneva, 2002). The synthesis of the set of criteria and indicators, suitable for assessing the course of the educational process, was carried out. Data to be analyzed at the University are the results of feedback from learners and teachers - results of the survey, testing, control of knowledge, and the data for the current and intermediate control enable management to conduct operational performance analysis and provide corrective or preventive actions. In this case, analysis of the results of the final control acquires an additional function to check the effectiveness of the corrective or preventive actions during the semester. For each set of estimates descriptive statistical values were calculated (statements), ranges of values are defined, rare combinations of the values of the statistical parameters have been studied. A set of performance indicators of quality training has been developed, which is a descriptive statistics (average, standard deviation, the coefficients of skewness and kurtosis).

The stability of the distribution of scores in the group of students was investigated, which determined that the variation of one point of one or more ratings in the examination sheet leads to qualitative changes in the statistical parameters, indicating the sensitivity of data levels, recorded by the monitoring, to the conditions of the test: there are certain regularities in their formation and the relationship in the proportions and, consequently, the scattering in the control data in a group of students is not random, and demonstrates various deviations.

Further, in the course of the experiment, statistical methods were applied (method of moments, the criterion of "three-sigma") (link) to help you determine deviations in the monitoring of educational activities. The rare combinations of values of the statistical parameters were studied and the psychological and pedagogical reasons for these deviations were analyzed. Consideration of the conditions, under which the corresponding extreme deviation data were found, has shown that reasons for the deviations are indeed a combination of circumstances, quite atypical for the educational process, requiring a detailed analysis of the situation and adjusting the educative process or control.

These indicators and the rules of their evaluation were the basis of the automated software module of monitoring the educational activities, including a package of data monitoring gauges, a database to store information, instruction and growth of the system, the data tools, and information visualization tools for managerial decision making.

At the final stage of the experiment the software module for monitoring was introduced in the educational activities of universities and tested during the academic year for various departments. Based on a survey of Chair heads and Deans' offices it was shown that the presented software does not only make it much easier to work with higher school records in administrative structures, but also provides information support for management decision-making on educational activities.

\section{Results}

\subsection{Determining the Structure of the Monitoring System of Educational Activities}

In management theory a significant contribution is given to the implementation of the feedback, diagnosing the condition and, if necessary, to adjusting the activities. By analogy, in the evaluation of educational activities to improve educational processes it is necessary to use the methodology of modern management, highlighting the control of learning in a special way, as well as pedagogical monitoring, quality of education diagnostics, rapid decision-making (Fig. 1). 


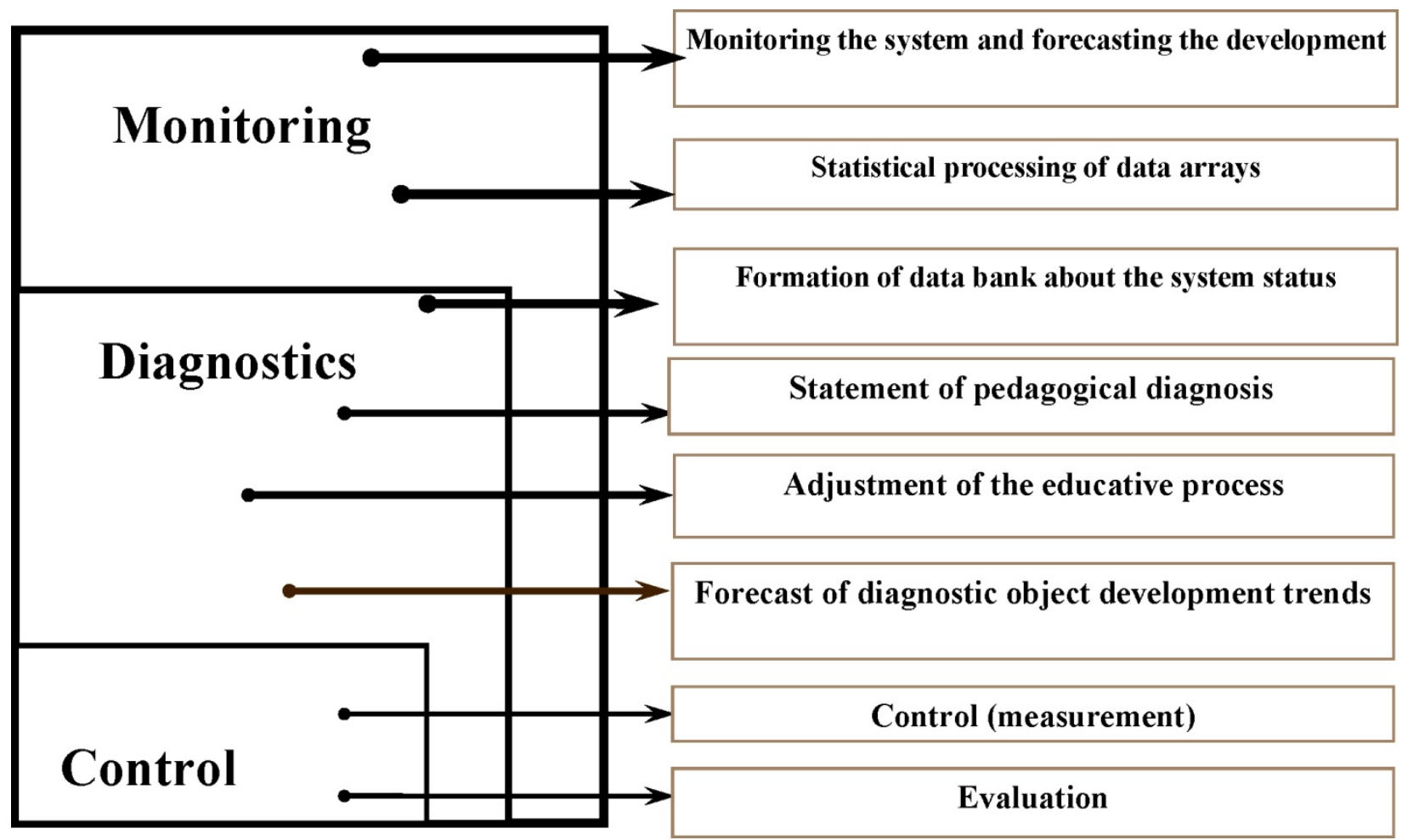

Figure 1. Components of pedagogical management at the University

The basis of the pedagogical management of educational activities consists of the results of pedagogical monitoring and diagnostics. Pedagogical diagnosis requires the definition of integral indicators characterizing the efficiency of the educational process, thus ensuring the required accuracy of educational measurement.

\subsection{Monitoring Indicators of Educational Activities in Higher School}

Data to be analyzed at the University are the results of feedback from learners and teachers - results of the survey, testing, control of knowledge, and the data for the current and intermediate control enable management to performance operational analysis and provide corrective or preventive action. In this case, analysis of the results of the final control acquires an additional function to check the effectiveness of the corrective or preventive actions during the semester.

Increasing the objectivity of the evaluation of the educational process is largely due to the level of formalization of pedagogical knowledge and its theoretical generalization. Using the qualimetric approach thus makes it possible to quantify the quality of any objects. Qualimetric technology of the quality assessment of educational activities at the University is based on the following principles:

-Informative value (a comprehensive view about the object);

-Integrity (a combination of qualitative and quantitative methods);

-Optimality (minimization of time, resources and assessment methodologies);

-Production effectiveness (reproducibility of results) and the availability of the use;

Experimental data of educational measurement has been verified (more than 500 testing results of student groups have been assessed: the intermediate tests, the results of tests and assessments, final exams). For the objects of the research the results of knowledge control in the fields of engineering, mathematics, education, economics and humanitarian disciplines were selected.

For each set of the estimates descriptive indicators were calculated and the analysis by the moment method and the method of "three-sigma" was carried out. The measured values that go beyond the typical ranges of the values were further explored. It is shown that the causes of these errors are combinations of circumstances that are quite atypical for the educative process, for example, a repeated exam; an easy material in the form of tasks used in the preparation of assignments for automated testing, etc. The resulting display (the degree of deviation 
of the results of statistical processing from the standard results) has been used in the algorithm of the monitoring system as an indicator that signals the need to pay attention to the parameters of the educative process and to investigate in detail its qualitative characteristics.

\subsection{The Use of Expert System Technology in Monitoring the Educational Activities of the University}

For the analysis of the incoming information into the database, and of the automated statistical calculation resulting indicators, for saving time and human resources, it seems necessary to use an expert system, which includes knowledge of a certain poorly structured and difficult to formalize domain and is able to offer and explain the reasonable solutions. The main components of an expert system are the knowledge base, the inferential mechanism (solver) and explanations subsystem.

The knowledge base of an expert system is a formal empirical knowledge of highly qualified specialists (experts) in some narrow subject domain and is designed to replace human resources. Such systems are used in areas where it is required to carry out the diagnosis of the current state of the object and to suggest possible ways to change this state based on the input data. As a "solver" of the system the tool of mathematical statistics is used, the explanations of the system are logical conclusions from the results of automated data processing.

To determine learning outcomes, a system of relative indicators (quantitative indicators) is used, reflecting a comparable basis of achievements in specific study areas of knowledge, forms of education, and their dynamics, obtained as a result of assessments, control and final testing. The purpose of such indicators is to enable comparison and recording of diverse information and values that influence the decision-making and the final assessment of learning outcomes. Forecasting of changes in the situation is due to the formulation of recommendations and management decisions based on statistical series of the collected data, the analysis of which is based on the processing of the raw data by mathematical methods.

For the proposed monitoring system (Fig. 2) a decision-making process scheme was selected, consisting of the following steps: calculations - comparisons - signal-recommendations. The first stage of the scheme is performed using mathematical (numerical) treatment of the initial data, and the others-with the use of knowledge rules. The systems of the set in the information environment decision rules form a weakly formalized knowledge base of expert system.

The monitoring data coming into the computer database are processed by an electronic expert, and statistical parameters are calculated, as well as a virtual model of the educational process is made. On the given set of confidence levels corridors of "normal" fluctuations of the phenomena parameters are made, that, by comparing the model with the new incoming monitoring results, to identify discrepancies, analyze the extent and reasons for the discrepancy between the expected and actual learning outcomes. Therewith such situations are revealed that differ substantially in their own determinable characteristics from typical situations, and, if it is necessary, recommendations are given for more detailed research by experts.

It is expected that with such an approach appropriate software will turn out to be a flexible research tool for the educational process, capable of self-training as part of a functioning monitoring system. As the database is embedded with more factual material and knowledge of experienced professionals, prerequisites for a more subtle differentiation of pedagogical phenomena are created, as well as for improvement of management efficiency. This authoring system can operate as a standalone module or as part of the information system of the University to meet the challenges of monitoring and management of educational activities. 


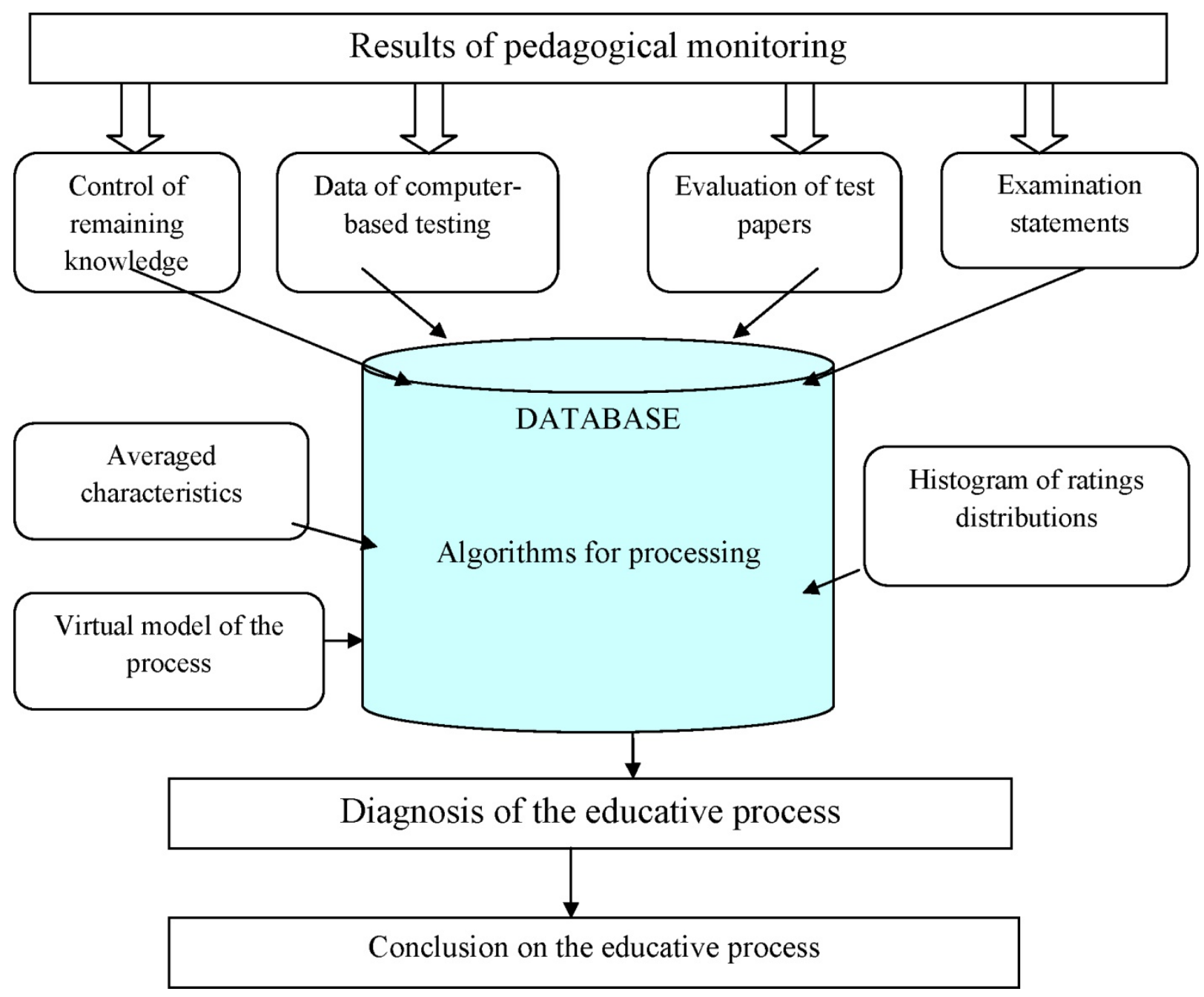

Figure 2. The general scheme of the software monitoring of educational activities module in higher school

\subsection{The Process and the Results of the Experiment}

The developed software module that enables monitoring of educational activities on the basis of the test results in student groups has been introduced into the educational process of departments and in Deans' offices of the two universities (of 7 Chairs (Ch) and 3 of Deans' Offices (D)). On the basis of the results of control tests of student groups entering the electronic database the educational progress processes within one academic year were monitored and diagnosed ( 8 control points, 6 assessments, 2 exams). After this period, the participating department heads were interviewed in the experiment in order to identify the effectiveness of the system as a way to support management decisions and operational quality control of the processes. The results of the survey are presented in Table 1. 
Table 1. Results of a survey to identify the effectiveness of the proposed system to support making management decisions

\begin{tabular}{|c|c|c|c|c|c|c|c|c|c|c|c|c|}
\hline $\begin{array}{l}\text { Evaluation } \\
\text { parameters }\end{array}$ & $\mathrm{Ch}_{1}$ & $\begin{array}{l}\text { Ch } \\
2\end{array}$ & $\begin{array}{l}\text { Ch } \\
3\end{array}$ & $\begin{array}{l}\text { Ch } \\
4\end{array}$ & $\begin{array}{l}\text { Ch } \\
5\end{array}$ & $\begin{array}{l}\text { Ch } \\
6\end{array}$ & $\begin{array}{l}\mathbf{C h} \\
7\end{array}$ & $\begin{array}{l}\text { Total for } \\
\text { the } \\
\text { Chairs, } \\
\text { on } \\
\text { average }\end{array}$ & $\mathbf{D}_{1}$ & $\mathbf{D}_{2}$ & $\mathbf{D}_{3}$ & $\begin{array}{l}\text { Total for } \\
\text { Dean's } \\
\text { Offices, on } \\
\text { average }\end{array}$ \\
\hline $\begin{array}{l}\text { Efficiency of the } \\
\text { system (\%) }\end{array}$ & 80 & 95 & 75 & 75 & 90 & 70 & 80 & 80.71 & 90 & 80 & 80 & 83.33 \\
\hline $\begin{array}{l}\text { The performance } \\
(\%)\end{array}$ & 100 & 90 & 90 & 90 & 100 & 90 & 100 & 94.29 & 100 & 100 & 90 & 96.67 \\
\hline Usability (\%) & 100 & 100 & 100 & 100 & 90 & 100 & 100 & 98.57 & 100 & 100 & 100 & 100.00 \\
\hline $\begin{array}{l}\text { Additional labor } \\
\text { costs, total }\end{array}$ & & & & & & & & & & & & \\
\hline (time, hour) & 2 & 1 & 2 & 2 & 1 & 1 & 2 & 1.57 & 2 & 2 & 2 & 2.00 \\
\hline
\end{tabular}

As it can be seen from the results of the software monitoring module user surveys (Heads of Departments of the University), the proposed software product at low cost and time and usability has high performance (95\%), that is, identifies problem characteristics of educational activities in higher school and has a fairly high efficiency ( $82 \%)$, to facilitate management decisions. The proposed system is a flexible tool for research of educational processes, capable of self-instruction as part of a functioning monitoring system and can be used to complement and improve the information system of university management, implementing managerial tasks of planning, recording, analysis, control, adjustment of educational processes.

\section{Discussions}

The need to support management decision-making at the University, to identify the problems in the educational activity under conditions of high information richness, set the task of developing a monitoring system in higher school based on the effectiveness of the educative process in student groups.

During the experiment, the development of monitoring software module based on the principles of operation of the expert system has been carried out, where indicative data and statistical methods of their evaluation are used as the decisive rules for diagnosing the educative processes, to assess the results of educational activities on students' achievements. The presented monitoring program model helps to determine the best ways to achieve educational goals, displays the status of the educational processes in student groups, determines the deviation of actual performance from the plan with determining the causes of these deviations, and serves for the improvement of the operational management.

\section{Conclusions}

The introduction of a software module for monitoring the management of the educational processes in the University allowed increasing objectivity, efficiency and speed of management decision-making. The proposed solution enables efficient planning of the educational process, reduces the complexity of data processing, and improves the accuracy of the information processing and the performance of management activities.

\section{Acknowledgments}

The authors thank all participants of this research for their kind cooperation.

\section{References}

Drucker, P. F., \& Makyarello, D. A. (2010). Management (p. 704). Moscow: Williams Publisher.

Granichina, O. A. (2008). Conceptual bases of quality control of the educational process in institutions of higher education. News RGPU named after AI Herzen, 11, 175-181.

Grinkrug, L. S. et al (2007). Monitoring the quality of higher education activities: Verge problems. Fundamental research, 10, 44-46.

Ivanchenko, D. A. (2011). Optimization of construction of information system of university management. Practice and analysis, 2, 40-48. 
Kadakin, V. V. et al (2001). Computer system for monitoring and diagnosing the quality of teaching. Integration of education, 4, 46-48.

Levina, E. Y. (2012). Control of education on the basis of quality management. Fundamental research, 11, 567-571.

Meskon, M. et al (2009). Fundamentals of Management (p. 672). Moscow: Williams Publisher.

Molchanov, I. S. (2002). Monitoring the sphere of higher education as a complex system of control and management of its development. Questions statistics, 11, 60-64.

Naser, A. A. (2011). Concept of information telecommunication network based institution structural and functional analysis information flows. Social and economic systems, 4, 56-61.

Selezneva, N. A. (2002). Quality of higher education as an object of systematic research (p. 95). Moscow: Research Center of the quality of training.

Subetto, A. I. (2000). Kvalitologiya education (p. 220). Moscow: Centre Publisher.

Tarsky, Y. I. (2004). Modeling methodology in the context of the study of pedagogical systems. Proceedings of the conference "Modeling social and educational systems" Perm (pp. 22-29). State University Press.

Tomilin, A. K. (2012). Internal quality control of education at the university. Engineering Education, 9, $42-49$.

\section{Copyrights}

Copyright for this article is retained by the author(s), with first publication rights granted to the journal. This is an open-access article distributed under the terms and conditions of the Creative Commons Attribution license (http://creativecommons.org/licenses/by/3.0/). 